\title{
La función de juzgar ¿Y quién juzga a quien juzga (...) y a quien juzga (...) y a quien juzga (...)?
}

SUMARIO:

I. Introducción.

II. Algunos presupuestos.

III. La elección de los juzgadores en el Perú.

IV. ¿Y quién juzga a quien juzga?

V. Conclusiones.

VI. Bibliografía. 


\title{
RESUMEN:
}

El presente trabajo busca tratar un tema siempre difícil como lo es el de la labor del juzgador en el Derecho. Resulta difícil determinar una forma de calificación capaz de señalar cuándo una decisión jurídica resulta o no apropiada. Uno podría llevar a cabo esta calificación apostando por ideales vinculados a la labor del juzgador; en este sentido, podríamos decir que aquél aplica las normas previamente establecidas sin descartar la posibilidad de generar interpretaciones de las mismas que contribuyan a crear nuevos criterios o nuevas reglas favorables a la sociedad. Si acaso no lo hiciese, entonces su labor estaría viciada. En este sentido, es objeto del presente trabajo preguntarse si acaso es posible que el juzgador se provea de mecanismos que le permitan mantener una actuación coherente y previsible, a fin de generar seguridad jurídica.

Palabras clave: juzgador, derecho, función, elección, consistencia.

\begin{abstract}
:
This paper seeks to address an always difficult issue such as that of the work of the judge in the Law. It is difficult to determine a form of qualification capable of indicating when a legal decision is appropriate or not. One could carry out this qualification by betting on ideals linked to the work of the judge; In this sense, we could say that it applies previously established norms without ruling out the possibility of generating interpretations of them that contribute to creating new criteria or new rules favorable to society. Likewise, we could say that this function must be exercised with autonomy and freedom, in order to ensure that decisions are not influenced by the interests of third parties.

If he did not do it that way, then his work would be flawed. In this sense, it is the object of the present work to ask if it is possible that the judge is provided with mechanisms that allow him to maintain a coherent and predictable action, in order to generate legal certainty.

Keywords: judge, law, function, election, consistency.
\end{abstract}

\section{INTRODUCCIÓN}

A manera de introducción a la problemática que es materia del presente trabajo, resulta oportuno hacer mención de un artículo que se publicó en el diario El País de España hace ya varios años, el cual se tituló "¿Quién Juzga a los Jueces?"'. Dicho artículo fue escrito por Bonifacio de la Cuadra, abogado y periodista que ha prestado atención a cuestiones políticas y jurídicas durante su trabajo.

En dicho artículo, puede verse lo siguiente:

(...) La responsabilidad de los jueces por decisiones atrabiliarias o no comprensibles es difícil de exigir, fuera de la corrección que puede provenir de los recursos que las partes interpongan contra tales resoluciones o de la difícil condena por prevaricación.

\section{(...)}

(...) las asociaciones judiciales se opusieron a la injerencia de los órganos de gobierno en la actividad jurisdiccional de los jueces y magistrados.

\section{(...)}

(...) La Asociación Profesional de la Magistratura -APM-, (...) aprobó una conclusión, según la cual "en ningún supuesto de ejercicio de la función jurisdiccional podrá iniciarse una actuación disciplinaría por parte de los órganos de gobierno del poder judicial".2

Sobre dicho artículo, quiero rescatar algunos puntos que considero relevantes en relación al presente trabajo. Cada uno de dichos puntos se plantea a manera de pregunta y respuesta a fin

1. Una versión digital de dicho artículo podrá encontrarse en el siguiente enlace: <https://elpais.com/diario/1995/10/14/espana/813625201 850215.html>

2. DE LA CUADRA, Bonifacio. "¿Quién Juzga a los Jueces?" En: Diario El País. España: 14 de octubre de 1995. Versión digital disponible en: $<$ https://elpais.com/diario/1995/10/14/espana/813625201 850215.html> 
de ir adentrándonos en la materia investigada. Estos puntos son los siguientes:

a) ¿Pueden los juzgadores - jueces y funcionarios de justicia administrativa - tomar decisiones arbitrarias o no comprensibles?

Por supuesto, todo juzgador es susceptible de errar o de actuar con segundas intenciones. Lo contrario sería caer en la ingenuidad de creer en la infalibilidad humana y en la ausencia plena de toda mala intención.

b) ¿Son los recursos impugnatorios - por ejemplo, las reclamaciones, las apelaciones, los recursos administrativos, y otros medios- suficientes para combatir el error o la mala intención de un juzgador?

Ante esta pregunta, uno se ve tentado a decir que sí; sin embargo, hay que tomar en cuenta que a veces un error o una corruptela no se encuentran solamente en un único funcionario; muchas veces dichos errores o corruptelas se encuentran en todo el aparato de juzgamiento - sea judicial o administrativo-, con lo cual el ciudadano no encuentra salidas.

c) ¿Es realmente indispensable la autonomía del juzgador, entendida como la no injerencia de otros funcionarios del Estado?

Nuevamente, la primera respuesta parece ser un contundente sí; sin embargo, ¿qué hacemos cuando es el propio juzgador el que ha caído en arbitrariedades? — sea por error o por mala intención-. Ello parece representar un aspecto aún no definido en materia jurídica. Igualmente, es válido decir que, si bien un gobernante podría intervenir en la labor del juzgador, luego nos preguntaremos ¿y quién juzgará a ese gobernante que juzgó al juzgador inicialmente cuestionado?
Estos puntos buscan mostrar que algunos de los presupuestos a los que estamos acostumbrados cuando hablamos de la función de juzgar merecen una nueva revisión. Así, el presente trabajo tiene el siguiente contenido:

a) Punto II. Algunos presupuestos: se describirán de forma breve los presupuestos conceptuales que dan origen a los poderes del estado y a la función de juzgar.

b) Punto III. La elección de los juzgadores en el Perú: se mostrará brevemente cuál es la mecánica de elección de juzgadores en el país, incluyendo tanto a los pertenecientes al poder judicial como a la administración pública.

c) Punto IV. ¿Y quién juzga a quien juzga?: se tratará el tema central del presente artículo, mostrando la problemática vinculada a la función de juzgar y al sujeto como controlador de la misma.

d) Punto V. Conclusiones: se llevará a cabo la exposición de las conclusiones del presente trabajo.

\section{ALGUNOS PRESUPUESTOS}

La función de juzgar es necesaria en el marco social para el mantenimiento de un orden. Dicha función se ubica dentro de la concepción de la sociedad, el Estado y el Derecho. La cuestión sobre el origen de estos elementos ha sido abordada por la filosofía -específicamente por la filosofía del derecho-.

Por ejemplo, John Locke ${ }^{3}$-1632-1704- consideró que el ser humano efectúo una renuncia a su libertad en el estado de naturaleza con la finalidad de encontrar una ley que ampare la convivencia pacífica. Esto implica una situación de igualdad, sin subordinación de unos a otros.

3. LOCKE, John. Segundo Tratado sobre el Gobierno Civil. Traducción, prólogo y notas de Carlos Mellizo. Madrid: Alianza Editorial, 1990. 
En el fondo, el gran motivo por el cual el ser humano se habría sometido a la sociedad sería la necesidad de seguridad frente a una naturaleza que lo amenaza en su condición de individuo. Al respecto, no podríamos pensar en seguridad sin el juzgamiento de las conductas no seguras que se dan dentro del marco de la sociedad, a la luz de las normas previamente establecidas.

En este punto, Thomas Hobbes ${ }^{4}-1588$ 1679- coincidiría en la idea del estado de naturaleza, pero diferiría en las características de dicho estado de las cosas. Así, siguiendo a Cortés Rodas 5 , para Hobbes el estado de naturaleza se encuentra caracterizado por la fuerza y la violencia.

Al respecto, Morales Godo 6 ha tenido a bien indicar que, efectivamente, el ser humano entra al orden social para obtener seguridad. Ante esto, el poder legislativo sería el primer y más importante poder del Estado, ya que establece las reglas de convivencia en base a la facultad otorgada a él por los miembros de la propia sociedad. En complemento al poder legislativo, el poder ejecutivo será aquél que monopolice la fuerza a fin de efectivizar las normas dadas por el poder legislativo.

Ahora bien, se deduce de lo anterior que las normas dadas por un ente legislativo requieren ser efectivizadas; es decir, no basta su enunciación, se requiere de elementos que lleven su aplicación a los hechos. Igualmente, es posible inferir que para llevar a cabo la aplicación de la norma a los hechos es necesario efectuar una calificación en la que el hecho y el supuesto de hecho de la norma se encuentran a fin de aplicar una consecuencia determinada. Así, casi de forma inevitable, debe aparecer también la figura de un juzgador capaz de reconocer cuándo se han incumplido las leyes establecidas, no sólo para declararlo sino también para tomar medidas tangibles al respecto, empleando la capacidad coercitiva del Estado.

De este modo, en las ideas de Charles Louis de Secondat, señor de la Brède y barón de Montesquieu, también conocido como "Montesquieu" -1689-1755-, podemos encontrar un primer bosquejo de lo que sería un juzgador y su función. De este modo, señaló que un juzgador no tenía que hacer más que simplemente aplicar la norma que ya les había sido dada para ello.

De modo específico, las palabras empleadas por Montesquieu son las siguientes: "Ahora bien, los jueces de la nación no son, según sabemos, sino la boca por donde habla la ley, seres inanimados que no pueden moderar ni su fuerza ni su rigor."

Si bien los aportes de Montesquieu son relevantes, es también cierto que hoy por hoy su concepción de la labor de juzgar resultaría insuficiente. Incluso tomando en cuenta la pretensión de contar con un conjunto de normas jurídicas claras y solemnes, las cuales deban aplicarse sin ser modificadas, el juzgador se verá en la necesidad de hacer más que sólo enunciar su contenido.

Ahondando en ello, el juzgador requerirá ver si los hechos manifestados calzan con los supuestos descritos en la norma. Al respecto, cabe decir que muchas veces los hechos llevarán a du-

4. HOBBES, Thomas. Leviatán. Edición preparada por Carlos Moya y Antonio Escohotado. Segunda Edición. Madrid: Editora Nacional, 1980.

5. CORTÉS, Francisco. "El contrato social liberal: John Locke". En: Revista Co-herencia, volumen 7, número 13: 2010, pp. 99-132.

6. MORALES, Juan. "La Función del Juez en una Sociedad Democrática". En: Revista de la Maestría en Derecho Procesal, volumen 4, número 1: 2010.

7. MONTESQUIEU. El espíritu de las Leyes. XI, VI. Tomo I. Librería General de Victoriano Suárez. Universidad de Sevilla. 1906. 
dar al juzgador, no siendo este capaz de decidir inmediatamente si los mismos calzan dentro de los supuestos descritos por aquella.

Igualmente, el juzgador no sólo deberá calzar los hechos suscitados con el supuesto de hecho de la norma determinada, también tendrá que valerse de elementos que le generen convicción suficiente para llegar a la conclusión de que los mismos ocurrieron tal y como le son narrados por las partes.

Dicho de otro modo, puede que la narración de los hechos sí coincida con lo descrito en los presupuestos de la norma; sin embargo, puede que no hayan acontecido de esa forma - o que no hayan acontecido en lo absoluto- en el plano de nuestra realidad perceptible.

Hasta aquí, podemos ver que, además de enunciar la norma fijada con anterioridad, el juzgador también tiene otras labores relacionadas a los hechos que se le exponen y a la derivación de normas que puedan complementar las ausencias o vacíos legislativos existentes. Así, resulta muy difícil sostener una idea en la que el juzgador es un mero autómata que cual si fuese una grabación repite una melodía determinada.

Sobre esto último, Pérez Luño ${ }^{8}$ señala que la visión de un juez estilo autómata implica que este se limita a aplicar las consecuencias previstas en las normas a hechos que son materia de juzgamiento. Dicha postura vería la función de juzgar como el encajar hechos en los supuestos de hecho y aplicarles consecuencias ya establecidas. El juzgador sería entonces un declarador y no un creador de Derecho.

Este breve recuento nos lleva a una interrogante interesante: comúnmente se dice que el poder viene directamente del pueblo; en dicho sentido, el poder legislativo es elegido por los ciudadanos quienes escogen a cada uno de los parlamentarios. Por otra parte, la cabeza del poder ejecutivo es igualmente elegida median- te votación. Sobre los juzgadores podríamos preguntarnos, ¿a ellos quiénes los eligen?

\section{LA ELECCIÓN DE LOS JUZGADORES EN EL PERÚ}

Es oportuno aclarar que los ciudadanos no escogen al cien por ciento de los miembros de los poderes ejecutivo y legislativo. Por ejemplo, el gobernante -que puede ser el presidente de la república, el primer ministro o quien corresponda según el país-, una vez elegido, escogerá él mismo a los encargados de los ministerios, pudiendo sí criticársele en la elección, pero no evitar que sea él quien la efectúe.

Igualmente, en lo que se refiere al poder legislativo, los ciudadanos escogerán como parlamentarios a los candidatos que prefieran, sea por cuestiones personales o partidarias; sin embargo, será cada parlamentario el que escoja a sus asistentes y otros trabajadores que compartan su despacho.

Dicho esto, quiero traer a colación que estos poderes del estado tienen un componente de elección directa proveniente de los ciudadanos y otro de elección indirecta, consistente en el hecho de que serán los designados por estos los que, a su vez, investidos con su nuevo cargo, escojan otros servidores públicos de distinto rango.

De otra parte, la elección del poder judicial no es igual a la descrita anteriormente. Si bien le llamamos "poder", el presupuesto de venir de una elección de los ciudadanos no funciona de la misma manera.

Así, en el Perú, los únicos jueces que son elegidos por voto popular son los jueces de paz, conforme al texto del artículo 152 de la Constitución Política de 1993, el que a la letra dice lo siguiente:

"Jueces de Paz y de Primera Instancia

8. PÉREZ, Antonio Enrique. “Qué significa juzgar?” En: Doxa, Cuadernos de Filosofía del Derecho, 32, Universidad de Sevilla: 2009, pp. 151-176. 
Artículo 152.- Los Jueces de Paz provienen de elección popular.

Dicha elección, sus requisitos, el desempeño jurisdiccional, la capacitación y la duración en sus cargos son normadas por ley.

La ley puede establecer la elección de los jueces de primera instancia y determinar los mecanismos pertinentes."

Sobre dicha norma, cabe añadir que la elección de jueces de paz se encuentra legislada por la Ley 29824, cuyo artículo 8 indica lo siguiente:

\section{"Artículo 8. Acceso al cargo}

El juez de paz accede al cargo a través de los siguientes mecanismos:

a) Por elección popular, con sujeción a la Ley Orgánica de Elecciones.

b) Por selección del Poder Judicial, con la activa participación de la población organizada."

La elección popular es la forma ordinaria de acceso al cargo. El mecanismo de selección se aplica sólo por excepción.

Ambos procesos son reglamentados por el Consejo Ejecutivo del Poder Judicial.

Así, vale la pena precisar que si bien tenemos un juez —el juez de paz- que puede ser elegido por voto popular, ello no ocurrirá así en todos los casos, previéndose también para él - para el juez de paz- un mecanismo de excepción en que será el propio poder judicial el que efectúe la elección.

Igualmente, no está de más traer a colación el caso de Bolivia. En dicho país se da una elección de juzgadores por voto popular; sin embargo, hay que decir que no se trata de una elección directa en sentido estricto. Dicho brevemente, a) La Asamblea Legislativa - de Bolivia- escoge a un conjunto de candidatos en base a un perfil profesional - considerando cuotas mínimas para mujeres y personas de los denominados pueblos originarios-.

b) Los candidatos serán aprobados por dos tercios de la Cámara de la Asamblea.

c) Luego de ello podrá efectuarse la elección ciudadana.

Igualmente, cabe indicar que el proceso aquí descrito no se da respecto de todos y cada uno de los jueces de dicho país sino respecto de algunos órganos de juzgamiento de no menor relevancia como el Tribunal Constitucional Boliviano.

Cerrando este breve recuento sobre el hermano país de Bolivia, cabe preguntarnos ¿cómo se eligen a los jueces en el Perú?

Sin perjuicio de lo señalado anteriormente sobre los jueces de Paz, la elección de los jueces de rango superior - Jueces de Paz Letrados, Jueces Especializados, etc. - , se realiza de manera indirecta, es decir, no por el voto de los ciudadanos.

A fin de entrar en mayor detalle, considero pertinente citar lo dicho por Belaunde ${ }^{9}$ sobre la forma en que se nombran a los jueces en el Perú:

"En el mundo occidental, existen dos grandes sistemas para nombrar a los jueces. O son nombrados por el poder político muchas veces mediante una designación conjunta del Ejecutivo y del Legislativo o en su defecto, son designados por órganos especializados en los cuales también interviene el Estado y en algunos países ciertos entes representativos de la sociedad civil. En el Perú hemos tenido

9. BELAUNDE, Martín. “Cómo se nombra a los jueces?"En: Diario La Razón. España: 18 de julio de 2018. Versión digital disponible en: <http://larazon.pe/2018/07/18/como-se-nombra-a-los-jueces/> 
ambos sistemas y ahora el nombramiento de los jueces y fiscales emana del desprestigiado CNM. ${ }^{10}(\ldots)^{\prime \prime}$

En el Perú la designación de los jueces conforme a la Constitución de 1933 emanaba del Poder Ejecutivo para jueces civiles, penales y vocales - ahora jueces - de las Cortes Superiores. Los vocales - hoy también juecesde la Corte Suprema eran propuestos por el Poder Ejecutivo mediante ternas remitidas al Congreso para que éste decidiera el nombramiento.

Ahora cabría otra pregunta, sabiendo que la Junta Nacional de Justicia-JNJ —antes CNMescogerá a los jueces, ¿quién elige a los miembros de la JNJ? Siendo breves, la elección será hecha luego de un concurso de méritos por una comisión especial, dicha comisión será conformada de la siguiente manera:

a) El Defensor del Pueblo.

b) El Presidente del Poder Judicial.

c) El Fiscal de la Nación.

d) El Presidente del Tribunal Constitucional.

e) El Contralor General de la República.

f) Un rector elegido en votación por los rectores de las universidades públicas licenciadas con más de 50 años de antigüedad.

g) Un rector elegido por los rectores de las universidades privadas licenciadas con más de 50 años de antigüedad.

Sin ánimo de entrar en mayor detalle, recuérdese que algunos de dichos miembros son a su vez elegidos por otro poder político - por ejemplo, el Defensor del Pueblo es escogido por el Congreso de la República o poder legislativo-. De esta manera, ¿es posible liberarse de la carga política en la elección de los jueces? Si la respuesta es negativa, ¿sería mejor que la elección sea mediante votación directa? Se trata de un tema difícil e interesante.
Ahora bien, como habrá podido apreciar el lector, el presente artículo habla de juzgador como una categoría que engloba tanto a los juzgadores del poder judicial -o ente que haga sus veces - como a los juzgadores de la administración pública.

Sobre los últimos - los juzgadores de la administración pública-, establezcamos las siguientes premisas:

a) En los distintos entes y órganos del Estado peruano existen órganos que se encargan de juzgar las controversias que puedan surgir entre los ciudadanos - o administrados-y la administración pública.

b) Dichos entes cumplen con el llamado principio de la doble instancia; dicho de otro modo, cuando uno no está de acuerdo con una de las decisiones que ha tomado la entidad determinada —o administraciónuno podrá solicitar al órgano que emitió el acto o decisión que reconsidere lo resuelto y/o también podrá recurrir al órgano superior inmediato - de la propia entidadcon la finalidad de que sea este último el que tome una decisión.

c) Por último, si todo lo decidido dentro de la propia administración no resulta del agrado del ciudadano, éste podrá recurrir al poder judicial para que sea este último el que decida sobre lo sucedido.

Dicho esto, tomemos en cuenta lo siguiente:

a) Es conocida aquella frase que dice "no ser juez y parte". Al respecto, ello significa tomar como principio que cuando se tiene relación con el problema o controversia en juego, la decisión final sobre la misma la debe tomar un tercero ajeno, el cual carezca de intereses personales respecto del asunto.

10. Cabe indicar que el Consejo Nacional de la Magistratura-CNM ha sido reemplazado por la Junta Nacional de Justicia-JNJ. 
b) Sobre ello, es oportuno recoger lo dicho por Cedeño ${ }^{11}$, al indicar que uno no es buen juez de su propia rectitud. La complacencia abriría sus pasos en dichas circunstancias. Esto se aplica a más de una situación en que aparezca la idea de un conflicto de intereses. Igualmente, a nivel de auditorías u otros actos de control se busca que el controlador no tenga relación con aquello que se controla. Del mismo modo, el denominado principio de separación de poderes seguiría el mismo presupuesto: no dejar todo en una misma mano, ya que ello puede suponer la desnaturalización de la figura esperada. Igualmente, en la ciencia existe un control de las teorías científicas que se basa en la corroboración. De este modo, la comunidad de científicos podrá efectuar las críticas que considere necesarias a efectos de lograr lo que finalmente quiere todo científico, el descubrimiento de nuevas verdades en relación al tema investigado. Si los científicos actuaran como juez y parte, entonces habría tantas teorías ad hoc que se perdería la verdadera finalidad de la ciencia.

Hasta aquí nos planteamos la siguiente pregunta ¿representa la posibilidad de ser juez y parte de la administración pública un inconveniente? Desde el punto de vista del presente trabajo la respuesta es sí - aunque no es materia del presente artículo entrar a fondo en ello-.

El otro punto relevante es igual al discutido respecto a los juzgadores del poder judicial. Así, la pregunta es ¿y cómo se escogen a los juzgadores que trabajan dentro de la administración pública?

Una respuesta íntegra requeriría algo más que las páginas del presente artículo; sin embargo, para los efectos de lo que nos interesa diremos que al igual que las empresas privadas tienen un conjunto de normas que determinan cómo se contrata a un trabajador, el sector público tiene varios conjuntos de normas a través de los cuales puede contratar a distintos trabajadores - llamados servidores públicos, funcionarios públicos, etcétera- bajo distintos parámetros. Así, por ejemplo, se pueden ver los siguientes conjuntos de normas bajo las cuáles el Estado contrata personal12:

\section{REGÍMENES LABORALES PARA SERVIDORES PÚBLICOS EN EL PERÚ}

\section{SERVICIO CIVIL}

\section{GENERALES}

\section{Carrera}

Administrativa (D. Leg. 276-1984)

Sin carrera con vínculo laboral

- Régimen de la actividad privada (D. Leg. 728-1991)

- Contratación Administrativa de Servicios-CAS

(D. Leg. 1057-2008 y modificado 2012)

\section{CARRERAS ESPECIALES}

- Profesorado y Magisterial (Ley 24029-1984

y Ley 29062-2007)

- Docentes universitarios (Ley 23733-1983)

- Profesionales de la salud (Ley 23536-1982)

- Asistenciales de la salud (Ley 28561-2005)

- Magistrados (Ley 29277-2008)

- Fiscales (D. Leg. 052-1981 y modificado 2010)

- Diplomáticos (Ley 28091-2003 y modificada 2005)

- Servidores penitenciarios (Ley 29709-2011)

- Militares y policías (Ley 28359-2004 y Ley 27238-1999)

\section{OTROS}

\section{Sin Carrera con vínculo laboral}

- Gerentes públicos (D. Leg. 1024-2008)

\section{Sin Carrera con vínculo civil}

- Convenios de administración con PNUD

- Fondo de Apoyo Gerencial (DL 25650-1992)

Vínculo civil: Locación de servicios (2009)

11. CEDEÑO, Álvaro. 'La virtud de no ser juez y parte en nuestras decisiones'. En: Diario La Nación. Costa Rica: 15 de junio de 2015. Versión digital disponible en: <https://www. nacion.com/economia/la-virtud-de-no-ser-juez-y-parte-en-nuestras-decisiones/SCU2H72BBFDFJOXDKXA2YG73PA/story/>

12. Cuadro de regímenes del servicio civil. Cuadro tomado del documento titulado "Los Regímenes Laborales en el Perú 2", elaborado por la Autoridad Nacional del Servicio Civil-SERVIR-, página 19. Ilustra las diferentes opciones existentes en el servicio civil. Disponible en: <https:// storage.servir.gob.pe/biblioteca/SERVIR\%20-\%20El\%20 servicio\%20civil\%20peruano\%20-\%20Cap2.PDF> 
¿Y cómo se llevan a la práctica estos conjuntos de normas? A través de convocatorias para que los interesados postulen a los puestos y pasen por un proceso de calificación por etapas hasta que quede un único ganador que obtiene el trabajo; es decir, un concurso público.

¿Y qué entidades del estado tienen funcionarios que ejercen la función de juzgar?

No son pocas y entre ellas podríamos contar a todas las municipalidades tanto distritales como regionales; a Essalud, a Indecopi, a la Superintendencia Nacional de Aduanas y de Administración Tributaria-SUNAT, a la Superintendencia Nacional de los Registros Públicos-SUNARP, a la Superintendencia de Transporte Terrestre de Personas, Carga y Mercancías-SUTRAM, entre otras.

Así, por ejemplo, uno fácilmente puede encontrar información sobre las distintas plazas que se ofrecen en entidades como INDECOPI ${ }^{13}$ :

\section{PUBLICACIÓN DE CONVOCATORIAS Solo informativo}

De acuerdo con el D.S. 003-2018-TR y D.S. 083-2019-PCM

\begin{tabular}{|l|c|}
\hline \multirow{2}{*}{$\begin{array}{l}\text { Convocatorias, } \\
\text { previo al inicio de } \\
\text { la postulación }\end{array}$} & Planillas \\
\cline { 2 - 2 } & CAS \\
\cline { 2 - 2 } & Prácticas \\
\hline
\end{tabular}

En este sentido, desarrollado el presente acápite, es importante observar lo siguiente:

a) Los juzgadores del poder judicial son elegidos de forma indirecta por los ciudadanos. A la larga, sucede algo similar con los juzgadores de la administración pública, ya que los altos cargos de ésta son escogidos por autoridades políticas y luego estas organizan la elección y convocatoria para otros cargos. Un ejemplo de esto puede ser el de la presidencia del INDECOPI Instituto Nacional de Defensa de la Competencia y de la Protección de la Propiedad Intelectual-, cuyo presidente es escogido por la Presidencia del Consejo de Ministros-PCM.

b) En ambos casos señalados en a), el control ciudadano respecto a la función de juzgar es indirecto y pequeño. No hay elecciones directas periódicas.

\section{IV. ¿Y QUIÉN JUZGA A QUIEN JUZGA?}

En base a lo visto, la función de juzgar está a cargo de personas cuya elección es indirecta cuando se trata de la perspectiva ciudadana. Igualmente, esto parece estar justificado en uno de los presupuestos de la administración de justicia: la autonomía e imparcialidad del juzgador. Entonces, ¿qué nos asegura que el juez o funcionario encargado de decidir un asunto jurídico no cometa errores y mantenga la imparcialidad? ¿Debe continuar la administración pública resolviendo los casos en que ella misma está involucrada? ¿Es la elección indirecta un presupuesto necesario para garantizar la independencia y autonomía de los juzgadores?

La evidencia de juzgadores con intereses personales y la existencia de decisiones jurídicas difíciles de asimilar a la luz del cuerpo normativo existente a nivel jurídico parecen decir que no hay un mecanismo que asegure que el juzgador sea siempre autónomo, imparcial ni tampoco infalible. Igualmente, parece que carecemos de una mecánica capaz de evitar que los casos de los ciudadanos frente a la administración pública tengan a esta última como juzgadora inicial de los mismos.

Ante esto, una idea que podría venir a la cabeza es la siguiente: ¿deberíamos tener a alguien

13. Cuadro de convocatoria. Cuadro tomado de la página web de INDECOPI. Disponible en: <https://www.indecopi. gob.pe/incorporacion-del-capital-humano> 
que juzgue el trabajo del juzgador a fin de que aplique el Derecho de la mejor manera posible y no caiga en una falta de autonomía e imparcialidad?

La respuesta tentadora es un sí; sin embargo, ¿Quién juzgará luego la labor de este nuevo personaje -al que para fines prácticos llamaré "X" —? ¿Llegará un "X1"? luego de ello, ¿vendrá "X2" para juzgar lo hecho por "X1"?

Este último comentario busca llegar a lo que considero la cuestión filosófica relevante inmiscuida en lo que se ha expuesto en el presente artículo: en materia jurídica, ¿puede el sujeto ser controlador de sí mismo? ¿Puede un sujeto controlar a otro sin que luego se tenga la necesidad de configurar un nuevo controlador para el primero de ellos?

Considero que no. Lo que requeriríamos es que los sujetos seamos capaces de reconocer un elemento objetivo, el cual no será precisamente un controlador sino más bien un parámetro común de evaluación del razonamiento de los juzgadores e incluso del cuerpo normativo que les sirve de base para la toma de sus decisiones. De este modo, la predictibilidad de las acciones de los juzgadores en materia jurídica no es una cuestión de amenazas ante procederes erróneos, sino de orden para generar una claridad y predictibilidad que resulten innegables y por ende inevitables.

Sin perjuicio de ello, hay que reconocer que uno podría pensar lo siguiente: "no importa el mecanismo que se emplee, siempre el sujeto podrá obviarlo en aras de sus propios fines". Desde luego, este es el mayor reto, este nuevo elemento debe ser tal que pueda transparentar la acción del juzgador incluso sin que él lo desee y a la vez no depender de otro sujeto a fin de no generar un bucle. Sólo así podremos llevar las cuestiones jurídicas fuera de las simples creencias - muchas veces formadas sin conocimiento de lo jurídico- para pasar a un mayor grado de certeza y predictibilidad.

Los ejemplos de lo que aquí se comenta no son pocos. Son varias las ocasiones en que un juzgador puede tomar decisiones impensadas por los usuarios del aparato jurídico. Si bien dichos casos serán materia de análisis y desarrollo en otro trabajo, no deja de ser oportuno mencionar al menos uno de ellos. En este sentido, a continuación se mostrará una decisión judicial que no parece ser acorde a la normatividad vigente. Dicha decisión se expondrá sin mención a su autor o a las partes procesales y destacando únicamente los fundamentos que resultan relevantes al presente trabajo. La decisión judicial mencionada es la siguiente:

\section{“X JUZGADO DE PAZ LETRADO (XXXX)}

$\begin{array}{ll}\text { EXPEDIENTE } & \text { : "Número" } \\ \text { MATERIA } & \text { : OBLIGACION DE DAR } \\ \text { SUMA DE DINERO } & \text { : "Juez X" } \\ \text { JUEZ } & \\ \text { ESPECIALISTA } & \text { : "Especialista X" } \\ \text { DEMANDADO } & \text { : "Demandado X" } \\ \text { DEMANDANTE } & \text { : "Demandante X" }\end{array}$

Resolución Nro.- "Número"

"Ciudad", "Fecha"

Del "Año".-

DADO CUENTA

Al escrito que antecede; $y$,

\section{CONSIDERANDO:}

El artículo IX del Título Preliminar del Código Procesal Civil precisa: "Las normas procesales contenidas en este Código son de carácter imperativo", (...) último párrafo del artículo 426 del Código Adjetivo: "si el demandante no cumpliera con lo ordenado a criterio del Juez, este rechaza la demanda y ordena el archivo del expediente"

\section{(...)}

Mediante resolución "Número X" de "fecha $X$ ", se declaró inadmisible la demanda que nos ocupa, otorgando al demandante un término prudente para que cumpla con subsanar la omisión anotada.

\section{(...)}


Se verifica de la revisión del escrito (...) no subsana los términos de la resolución de inadmisibilidad (...) del referido contrato de arrendamiento que ha sido materia de calificación, no existe cláusula y/o penalidad alguna donde el demandado se comprometa al pago de arriendos durante el tiempo que se encuentre en posesión del inmueble después del vencimiento (...), por ende, no se encuentra acreditada plenamente la relación obligacional. Por las consideraciones expuestas y estando a los dispositivos acotados:

\section{SE RESUELVE: (...) RECHAZAR LA DEMANDA} (...).

Ahora bien, visto lo decidido por un juzgador determinado, corresponde ver si ello podría traer alguna preocupación en el sentido de lo expuesto en el presente trabajo. Al respecto, es importante que el lector tenga presente las siguientes normas:

\section{CÓDIGO CIVIL}

Artículo 1700.- Vencido el plazo del contrato, si el arrendatario permanece en el uso del bien arrendado, no se entiende que hay renovación tácita, sino la continuación del arrendamiento, bajo sus mismas estipulaciones, hasta que el arrendador solicite su devolución, la cual puede pedir en cualquier momento.

\section{CÓDIGO PROCESAL CIVIL}

\section{Artículo 688.- Títulos ejecutivos}

Sólo se puede promover ejecución en virtud de títulos ejecutivos de naturaleza judicial o extrajudicial según sea el caso. Son títulos ejecutivos los siguientes:

\section{(...)}

9. El documento impago de renta por arrendamiento, siempre que se acredite instrumentalmente la relación contractual;

\section{$(\ldots)^{\prime \prime}$}

Entonces, ¿qué sucedió en el caso que describe la resolución citada?

Una persona cumplía con los supuestos del artículo 1700 del Código Civil y quiso hacer valer el cobro de la deuda a su favor en base al artículo 688 del Código Procesal Civil, siendo que esto último lo debe hacer ante un juez. Para justificar su decisión, el juez emplea el numeral 9 del artículo 688 del Código Procesal Civil, exigiendo que se acredite la relación obligacional mediante prueba instrumental, con lo cual concluye que la obligación de pago una vez vencido el contrato debe estar contenida en el propio contrato de arrendamiento.

Ante esto la pregunta es ¿y para qué sirve el artículo 1700 del Código Civil? Si nos atenemos a lo decidido por el juzgador, llegaremos a la conclusión de que dicho artículo no tiene utilidad alguna. Las partes podrían haber pactado que los pagos continúan luego de vencido el contrato con o sin la existencia de la referida norma.

En mi humilde opinión, esto califica como un absurdo ${ }^{14}$. ¿Por qué? Ello se debe a que si aceptamos lo decidido por el juzgador en este caso entonces tendremos que admitir que entre el artículo 1700 del Código Civil y el numeral 9 del artículo 688 del Código Procesal Civil existe una contradicción. Dicho de otro modo, el numeral 9 del artículo 688 del Código Procesal Civil estaría indicando que la acreditación de la relación contractual mediante prueba instrumental supone que la obligación de pago luego de vencido el contrato se encuentre escrita en el documento. Ello resulta contradictorio con el artículo 1700 del Código Civil, norma con igual rango que indica que la continuación del arrendamiento bajo sus mismas estipulaciones es una consecuencia del simple vencimiento del plazo del contrato. Asimismo, es de notar que el numeral 9 del artículo 688 del Código Procesal Civil es una disposición que quiere tener certeza sobre la existencia de un contrato.

14. Entiéndase por absurdo un razonamiento que al desarrollarse de forma deductiva lleva a contradicción. 
Como es sabido, el contrato puede ser verbal o escrito; sin embargo, es su versión documentada o escrita la que da facilidad probatoria. En este sentido, lo que dicha norma exige es que se acredite la existencia de un contrato mediante un acuerdo escrito a fin de que el juzgador tenga en qué apoyar su decisión.

En el caso presentado, el demandante sí presentó el contrato y con ello acreditó la relación contractual —cumpliendo con el numeral 9 del artículo 688 del Código Procesal Civil-. El decisor tenía que seguir empleando las normas para llevar a cabo la aplicación del Derecho al caso, incluyendo al artículo 1700 del Código Civil como un dispositivo que hace emanar la obligación de pago de la ley; sin embargo, optó por generar una contradicción entre los artículos ya mencionados. ${ }^{15}$

Ante esto, es posible preguntarse si acaso las decisiones de los juzgadores en general no deberían seguir al menos un parámetro de consistencia ${ }^{16}$. Desde mi punto de vista la respuesta es que sí.

\section{CONCLUSIONES ${ }^{17}$}

a) En materia jurídica, uno de los temas pendientes es cómo lograr un buen ejercicio de la función de juzgar, evitando así las arbitrariedades y los errores.

b) La instauración de mecanismos de control para los juzgadores no es un asunto pacífi$\mathrm{co}$, ello tiene como inconveniente que las injerencias en su labor pueden tomarse como falta de autonomía e imparcialidad.

c) La forma en que se escogen a los juzgadores tampoco representa una garantía de la imparcialidad ni la efectividad deseada, puesto que en última instancia los escoge el poder político instaurado.

d) Cuando se trata de la función de juzgar, deberíamos considerar la posibilidad de buscar un parámetro de evaluación. Así, teniendo como vaso comunicante este modo de razonamiento, sería más sencillo generar una calificación del desempeño de la labor de juzgar sin que se vea como injerencia y pérdida de autonomía e imparcialidad.

e) Las decisiones jurídicas en general deberían asumir al menos un parámetro de consistencia - entendido ello desde la lógica formal- a fin de evitar que sea el propio juzgador el generador de más situaciones problemáticas.

15. Téngase presente que la consecuencia factual de esta situación es que el inquilino precario permanecerá en el inmueble sin tener que asumir obligación de pago alguna por los meses que transcurran de esa forma.

16. Entiéndase por consistencia, por lo menos, la no presencia de contradicciones.

17. Para la elaboración de este artículo se consultó: CORREA, Rodrigo P. "El Gobierno Judicial ante la Constitución". En: Revista de Estudios de la Justicia № 6. Facultad de Derecho de la Universidad de Chile. Chile: 2005, pp. 117-126. 